\title{
Los procesos de etnogénesis en Santiago del Estero. Hacia una historicidad de las identidades étnicas
}

Ethnogenesis processes in Santiago del Estero. Towards a historicity of ethnic identities

\section{Carlos Bonetti}

\section{(Q) OpenEdition}

Electronic version

URL: https://journals.openedition.org/corpusarchivos/5267

DOI: 10.4000/corpusarchivos.5267

ISSN: 1853-8037

\section{Publisher}

Diego Escolar

\section{Electronic reference}

Carlos Bonetti, «Los procesos de etnogénesis en Santiago del Estero. Hacia una historicidad de las identidades étnicas», Corpus [En línea], Vol. 11, №. 2 | 2021, Publicado el 22 diciembre 2021 consultado el 26 diciembre 2021. URL: http://journals.openedition.org/corpusarchivos/5267 ; DOI: https://doi.org/10.4000/corpusarchivos.5267

This text was automatically generated on 26 December 2021. 


\title{
Los procesos de etnogénesis en Santiago del Estero. Hacia una historicidad de las identidades étnicas
}

\author{
Ethnogenesis processes in Santiago del Estero. Towards a historicity of ethnic \\ identities
}

Carlos Bonetti

\section{EDITOR'S NOTE}

Fecha de recepción del original: 1/07/2021

Fecha de aceptación para publicación: 29/10/2021

\section{Introducción}

1 El presente trabajo aborda los procesos de etnogénesis o reemergencias étnicas que comenzaron a manifestarse en el contexto provincial hacia fines de la década de los 90 . Particularmente nos interesa situarnos en la historicidad de las identidades étnicas y rurales para dar cuenta de lo que Escolar (2007) señala como "experiencias sociales de larga duración" (p. 21), entendiendo que las reivindicaciones étnicas actuales no solo son el producto de ciertos contextos de posibilidades, sino que también responden a una trama histórica muchas veces subterránea y generalmente invisibilizada, donde se vuelve necesario revisar el pasado en términos de categorías, significaciones e imaginarios en pugna. Este posicionamiento, tomando la concepción de aboriginalidad desarrollada por Beckett (1988) y profundizada por Briones (1996), ${ }^{1}$ nos permite escapar de los polos desde donde generalmente se la piensa, ya sea como una identidad que merece peritarse para determinar su autenticidad -como si fuesen posibles 
continuidades históricas inalterables que asegurarían una identidad "indígena pura"-, o bien a partir del criterio del autorreconocimiento asumido por el Estado que muchas veces tiende a reducir toda la trama de complejidades históricas y políticas -en ocasiones atravesada por posturas esencialistas-y que se traduce en ciertos problemas al momento de visibilizar a la población indígena en los registros poblacionales, como en el caso de los censos.

2 En Santiago del Estero son escasos los antecedentes de investigaciones empíricas sobre los procesos de reetnización, ya que generalmente se hizo hincapié en el pasado indígena colonial desde la etnohistoria o bien centrado en memorias indias del campesinado no autorreconocido como pueblo originario. ${ }^{2}$ Esta vacancia nos invita a formularnos una serie de interrogantes que se complejizan en un escenario con predominio del campesino en el sector rural y con una organización que lo posiciona como sujeto político en las últimas décadas como lo es el MOCASE (Movimiento Campesino de Santiago del Estero). Esta particularidad nos arroja un "mapa de diversidad interior" en la que se reconoce a los pueblos originarios y al campesinado como dos actores diferenciados, pero que comenzaron a articularse a partir de que algunos sectores iniciaron sus procesos de reconocimiento en el marco del mismo movimiento. Igualmente, en términos identitarios, los imaginarios suelen atribuir características esenciales al sector campesino en tanto es considerado como la matriz identitaria provincial; mientras que los pueblos originarios aún no son completamente asumidos por las subjetividades locales y terminan siendo objeto de miradas negacionistas en las que predomina un señalamiento de ausencia de autenticidad cultural por considerarlos "faltos" de continuidad histórica, ${ }^{3}$ o en su extremo, a partir de perspectivas subjetivistas que tienden a apoyarse en la autoafirmación como criterio definitorio. Esta última postura, si bien posibilitó de una manera directa el acceso y la garantía de derechos, en muchas ocasiones se vio en la necesidad de reproducir una imagen colonialista y a veces romantizada del indígena en la que se necesitaba reflejar una etnicidad prehispánica inalterable como un fundamento de derecho.

3 En la actualidad se registran, según el INAI, 79 comunidades con personería jurídica o con relevamiento técnico, jurídico y catastral, la mayoría perteneciente al pueblo tonocoté, y las demás distribuidas en los pueblos vilela, lule vilela, diaguita (cacano), guaycurú y sanavirón que se encuentran distribuidos en una gran extensión de la geografía provincial. Este importante número de comunidades (sobrepasa a varias provincias y se encuentra en tercer lugar en el NOA) refleja la aceleración del autorreconocimiento desde mediados de la década del 2000 con la inscripción de personería jurídica y los relevamientos territoriales culminados o en trámite. Si bien las etnogénesis son interpretadas a la luz de la coyuntura de la globalización y de sus consecuencias en términos de visibilización de nuevas identidades o de otras negadas al poner en evidencia el sentido histórico y arbitrario de la construcción de los Estadosnaciones (Boccara, 2001), es necesario anclarnos en las particularidades locales para la comprensión de estas emergencias en una provincia periférica con un sector rural empobrecido y atravesada por conflictos territoriales, producto del corrimiento de la frontera agropecuaria y del acaparamiento de grandes extensiones de tierras. Es así que las reetnizaciones también responden a una razón instrumental con el objetivo de la defensa territorial a través de legislaciones y de mecanismos jurídicos estatales de protección de los derechos indígenas. Con ello, para nada queremos argumentar que se trata de su única razón, sino de evidenciar una dimensión importante en las estrategias 
de lucha territorial y de conservación de los recursos del monte. En tal sentido, es necesario destacar que la etnogénesis no es un hecho homogéneo, y que el tránsito por este proceso, como el posicionamiento político asumido del "ser indígena", se hace evidente en los distintos pueblos, algunos de los cuales se encuentran comprendidos dentro del mismo MOCASE Vía Campesina ${ }^{4}$ y con acciones colectivas en términos de demandas por el derecho a la tierra y los territorios, mientras que otros con mayor presencia en el espacio público tienden a tematizar y visibilizar la cultura indígena.

Como dijimos, este trabajo se propone interpretar las reemergencias desde una dimensión histórica a largo plazo, tendiente a interpelar las perspectivas que buscan la continuidad de una identidad estática y otras que reducen la complejidad del proceso al plano de las subjetividades de los actores. En ese sentido, la interpelación de las identidades parte del hecho de entender que las mismas no existen por fuera de los discursos y las representaciones, y que siempre se conjugan en el escenario de las diferencias (Hall, 2010 [1989]). De este modo, siguiendo a Stuart Hall, la etnicidad es el puente para pensar la relación identidad-diferencia, es una suerte de reajuste de las mismas.

5 Nuestro primer argumento es que la etnogénesis en la provincia fue producto de los avances constitucionales y del reconocimiento de derechos de las poblaciones indígenas, lo que posibilitó en paralelo la activación colectiva de una memoria silenciada, fragmentada y ambigua en torno a lo indio, su representación y formas de vinculación. Es decir que las transformaciones jurídicas y los avances en reconocimientos de derecho repercutieron en las propias identidades en un contexto de cambios coyunturales como parte de la modernidad tardía. En tal sentido, el reconocimiento a la preexistencia en la reforma constitucional de 1994, así como otros avances en el plano legal, fue producto de una serie de demandas indígenas durante la década de los 90 en provincias como Neuquén, Salta y Chaco atravesadas por los conflictos de tierras (Gordillo y Hirsch, 2010), momento en el que Santiago aún no había visibilizado población indígena y el proceso de autorreconocimiento no había sido puesto en marcha. Era el MOCASE y el campesino como sujeto político visible el único actor en las demandas territoriales. Es hacia fines de esa década, pero fundamentalmente entre mediados de la primera y segunda de este siglo, que comienzan a emerger los pueblos originarios a partir de haber conseguido, o estar tramitando, la personería jurídica ante el INAI.

6 El segundo argumento, que se desprende del primero, es que el discurso de invisibilización (sobre todo a partir de la mestización) por parte de agentes estatales e intelectuales desde la segunda década del siglo XIX - con la desaparición de la figura de pueblos de indios- produjo una negación de la presencia del sujeto indígena, no así de la cultura en términos de herencia, profundizándose esta concepción durante el transcurso del siglo XX. Sin embargo, esta invisibilización no suprimió la presencia de memorias indias sostenida en gran parte por el campesinado, así como tampoco de la misma categoría colonial de indio que subterráneamente logró pervivir y que sirvió como criterio de marcación, como lo observa Rodríguez (2019) para el caso de Tucumán.

7 Estos argumentos se desarrollan en tres ejes: a) el indígena invisible/visible en los distintos relevamientos; b) la alteridad en la formación de la identidad provincial a través de los discursos políticos/intelectuales de fines del XIX y primera mitad del XX; 
c) la identidad indígena a partir de la etnicidad del campesinado donde se ponen en juego - no sin ambigüedades- memorias e identidades.

\section{Censos y relevamientos: entre la legibilidad e ilegibilidad de lo indígena}

8 Aclaramos que en esta sección no se propone un análisis de la evolución demográfica de la población marcada como indígena, teniendo en cuenta el origen y la naturaleza diversa de las fuentes que hacen imposible ese seguimiento y comparación, sino de evidenciar las formas en las que se visibiliza o invisibiliza en distintos relevamientos, para ayudarnos a pensar en los posibles criterios de clasificación y en la plasticidad de una categoría que dejó de ser étnica para reconvertirse en una condición jurídica-fiscal hacia fines de la Colonia (Farberman, 2019), más tarde esencialmente social, y actualmente en un retorno político a la etnicidad. El análisis histórico de la complejidad en la determinación del significante indio, indígena o pueblo originario nos permite también comprender el modo en que la indianidad se manifiesta en los censos y relevamientos recientes como una nueva manera de entender los criterios de etnicidad por parte del Estado.

9 Sabemos que el indio como categoría colonial fue parte de una política reduccionista en toda América para simplificar la complejidad de la diversidad cultural y lingüística al someter a los nativos a una relación de dominación; de allí que esta categoría se considere como supraétnica, como lo sostiene el ya clásico planteo de Bonfil Batalla (1972). Sin embargo, es necesario revisar cómo esta indianización se manifestó en distintas zonas para analizar no solo las consecuencias de la conquista y colonización, sino también cómo este concepto logró sobrevivir adaptándose en los diferentes periodos históricos y actualmente funcionando como una marcación identitaria, no solo por parte de sectores medios o altos urbanos, sino también de las mismas poblaciones rurales/campesinas en las propias representaciones del pasado y las (des)vinculaciones que desde allí se generan.

Los documentos coloniales tardíos del siglo XVIII nos sugieren la consolidación del indio como condición social y fiscal sin una distinción étnica particular y bajo un esquema de organización social y política a la usanza española en los pueblos de indios. Los distintos empadronamientos nos muestran categorías que van desde la condición de tributación hasta los diferentes roles o posiciones en el marco de las relaciones de poder y de acuerdo a las circunstancias políticas de los distintos periodos. Como sabemos, la etnicidad no era una preocupación de los administradores coloniales, quedando en manos de los jesuitas la tarea de describir y trazar un cuadro de las particularidades étnicas y lingüísticas de las sociedades indígenas. ${ }^{5}$ Los escasos y fragmentados documentos del siglo XVII nos permiten advertir ciertos indicios de este proceso de "borramiento" de las identidades y de los esfuerzos para reorganizarla en función de los esquemas dominantes, como el hecho de la organización de las familias a partir de formas de filiación occidental o en la generalización del quichua como lengua dominante que convivió con otras, como el tonokoté y el cacán, pero que luego las terminó suprimiendo. La lengua fue un vehículo importante en el proceso de indianización, a tal punto que la evangelización se realizó en quichua (o lengua general del Perú) y su expansión fue tal que se conservó como lengua de comunicación en las zonas rurales de un campesinado desmarcado étnicamente y en sectores urbanos. 
11 Determinar demográficamente la población indígena es un asunto complejo, fundamentalmente por la ausencia de documentación temprana, pero también debido a los sesgos de los propios padrones, censos y otros relevamientos, a los que se suman los mismos procesos de mestizaje que impactaron en los criterios locales para definir con precisión la pertenencia a una determinada casta. Las estimaciones que conocemos hasta el momento señalan unos 125.000 indígenas en las cercanías de los ríos Dulce y Salado, y entre 400.000 y 500.000 para la Gobernación del Tucumán hacia la finalización del siglo XVI (Pucci, 1998). A principios del XVII las fuentes señalan la estrepitosa caída demográfica como consecuencia de la sobreexplotación en las encomiendas, tal como se refleja en los 19 repartimientos de indios en la zona del río Salado durante 1607, que contenían un total de 4.796 indígenas entre caciques, tributarios, indias de hilado, reservados y jóvenes. ${ }^{6}$ Un año después, el censo realizado en la ciudad de Santiago destaca la disminución poblacional al sostener que de un número cercano a los 20.000 indígenas solo quedaban cerca de $5.000 .^{7}$ En esos momentos las alicaídas encomiendas eran alimentadas por desnaturalizaciones y desmembramientos de sociedades indígenas que se producían por las intervenciones militares en los valles calchaquíes y en el Chaco Gualamba, como se infiere de los registros del pueblo de Asingasta en el que conviven diferentes parcialidades con sus propios caciques. ${ }^{8}$

Hacia el siglo XVIII los relevamientos fiscales se fueron afinando, y a partir de las Reformas Borbónicas se introdujeron cambios y agregados en las categorías, visibilizando una diversidad y complejidad poblacional en los mismos pueblos. Los registros reduccionistas y ajustados dieron paso al reconocimiento de otras castas convivientes, a la visibilización de la mujer y de formas de ocupación territorial para discriminar entre originarios y forasteros, con o sin tierras. El último padrón de 1807 registra un total de 3.278 indígenas (consignando los ausentes) residiendo en los 16 pueblos que pervivían en una gran extensión de la mesopotamia santiagueña. ${ }^{9}$ A partir de allí serán otros registros -como los eclesiales y judiciales- los únicos que harán referencia, con muchas ambigüedades e imprecisiones, a la población indígena de la jurisdicción. El problema de identificar con claridad al indígena se vuelve notorio en registros eclesiales como los libros matrimoniales, donde muchos comienzan a cambiar su condición y a ser caracterizados como mestizos, incluso pardos, que son anotados como indios o mestizos. Esta fragilidad e imprecisión para la distinción de las castas subsume al indígena bajo otras categorías, y si ya era una condición poco precisa a esa altura, estos registros terminan por volverla más elástica y sujeta a las percepciones raciales de los sacerdotes. Al comparar padrones con actas matrimoniales del curato de Soconcho observamos esos cambios en las categorías étnico-raciales, como en la familia Sandi, identificada generalmente como indígena residente en el pueblo de Soconcho durante los empadronamientos coloniales. ${ }^{10}$ Así, en 1786, en el padrón de indios se registra a Francisca Paula Sandi, casada con Roque Anchava del pueblo de Umamaq, y a su hijo Manuel, y en las actas matrimoniales de 1812 Manuel aparece casado con Rafaela Gramajo bajo la etiqueta de mestizos. Incluso estas diferencias suelen aparecer dentro del mismo libro. Si bien un criterio podría haber sido la identificación de la casta de uno de los contrayentes o alguna normativa como las pragmáticas, la relatividad de las categorías produce una imposibilidad de seguimiento de la población indígena que de a poco comienza a ser englobada en este tipo de registro bajo el genérico de mestizos. Asimismo, los contrayentes sin identificación alguna demuestran las dificultades para la delimitación étnico-racial. 
13 El inicio del siglo XIX marca la desaparición de los pueblos de indios coloniales en la jurisdicción. Hacia 1816 las tierras comunales son puestas en arrendamiento y en 1818 rematadas por el fisco. Los principales compradores provenían de sectores de elites que arrastraban esa posición desde la Colonia y que tenían cierto acercamiento a estos viejos pueblos, ya sea como parientes de encomenderos, o por haber tenido alguna relación comercial o de conchabo con los indios. A ello se agregaba cierto conocimiento de las condiciones de estas tierras para la producción y la potencial mano de obra que podían significar los indios que todavía permanecían en condiciones de precariedad económica y jurídica.

14 Para 1818 se rematan pueblos como Manogasta, Pitambalá, Sumamao, Salavina, Sabagasta y Anchanga, para lo cual el gobierno, con intervención de Manuel Belgrano, dispone mediante decreto un relevamiento de los terrenos con la finalidad de contar con un registro en lo que refiere a la capacidad productiva (pastoril y agrícola) así como de aquellas familias de indios que todavía estaban asentadas. El objetivo de este plan era realizar un traspaso "ordenado" de estas tierras, pero principalmente establecer un “justo precio" en virtud de las condiciones productivas y quizás, implícitamente, de la mano de obra india disponible. Sin embargo, queda en las sombras la condición y el destino de los indios residentes, lo que constituye en sí un interrogante aún no resuelto en los estudios coloniales de la provincia (Farberman, 2008; Bonetti, 2016).

Farberman (2008) menciona un documento de Matará donde el cura párroco previene a las autoridades, ante la venta de los pueblos, que los indios amenazan con retirarse de las tierras en el caso de venta, situación que parece concretarse cuando en un registro posterior se advierte la desaparición de muchos de los "apellidos indios". En ese caso, la ausencia del pueblo evidencia una migración cuyo destino desconocemos, pero también otros indicios nos muestran la permanencia como peones agregados a los nuevos propietarios de la tierra. Es decir, algunas familias adquirirán la condición de agregados a las tierras que en muchos casos fueron de su propiedad.

16 A la par de la desaparición de los pueblos de indios -muchos de los cuales se convirtieron en estancias- se esfuma la categoría de indio de la documentación oficial. Más allá de los relevamientos de milicias y de algunos registros vitales donde hay marcaciones raciales a partir de descripción de características fenotípicas, como color de ojos, cabellos y nariz (donde se oculta lo indígena), no encontramos otros tipos de relevamientos donde pueda visibilizarse esta condición. Es en el censo nacional de 1869 donde (re)aparece oficialmente la categoría de indio para referirse a aquella población chaqueña sometida a partir de las excursiones militares y de las desnaturalizaciones, producto del avance del Estado provincial al interior del Chaco. Las capturas durante los malones, o a partir de distintas estrategias militares y de reducción a través de la evangelización, se ven reflejadas en la presencia indígena en diversas localidades del área rural y de la propia capital, generalmente en la condición de sirvientes en quintas de la ciudad y otras zonas como Copo, Sumampa y Fortines de la Frontera. De esta manera, en las columnas de apellido o de nacionalidad del censo se registra la indianidad de distintas maneras: "India del Chaco"; "Indio"; "Chaco Gualamba" o simplemente "Chaco" con algunas excepciones étnicas donde se menciona chiriguano y un grupo de los denominados matacos, compuesto por un cacique y 16 indios registrados como jornaleros en la propiedad de Félix María Padilla en el departamento de Copo 2. 
17 En el segundo censo de 1895 desaparece todo rastro indígena, salvo en muy pocos casos donde figuran sirvientes menores de edad de origen chaqueño de los que sospechamos pertenencia a alguna parcialidad. Incluso, todos los mencionados como indios chaqueños en el censo anterior desaparecen bajo esa condición. Aquí es importante señalar dos aspectos: la desaparición de la marca indígena -por lo menos en los registros oficiales-de los pobladores de la jurisdicción santiagueña, ahora caracterizados como habitantes de la campaña o gauchos en un contexto de expansión territorial del Estado provincial sobre el Chaco, de definición de sus límites y de la propia identidad. La alteridad indígena hacia mediados del XIX comienza a estar representada en las parcialidades identificadas como mocovíes, abipones y montaraces que habitaban en las periferias de la provincia y que circundaban en los límites con el Chaco desde el cual arremetían con malones a las poblaciones criollas de cercanía. Estas incursiones se convierten en una preocupación constante por lo menos hasta la primera década del siglo XX. Por otra parte, la expansión del desarrollo de un capitalismo periférico a partir del ferrocarril, de la instalación de obrajes e industrias, y de un mercado de tierras en crecimiento, representa el contexto en el que el Estado comienza a problematizar y a pensar cómo insertar las identidades rurales en el marco de las ideas de progreso y civilidad.

18 En tal sentido, los esquemas censales representan ese intento por simplificar la sociedad y hacerla legible en términos de dominación estatal (Scott, 1998). Lo cierto es que a partir de allí el Estado ya no visibiliza -no hace legible- a la población indígena, estableciendo otras categorías de estratificación social sustentadas en el trabajo/oficio/ profesión como indicadores de la posición de clase como nuevo criterio de identificación.

19 Luego de un gran salto hacia comienzos del siglo XXI cuando se instala la necesidad de registrar en los censos a la población indígena, y luego de otros intentos como en la década del 60, es que se vuelve visible su presencia en la provincia, esta vez bajo un proceso nuevo de etnogénesis, entendiéndolo en los términos de las ampliaciones y resignificaciones que fue cobrando el concepto de Sturtevant (1971), en tanto no solo como producto de una emergencia física, sino de apropiaciones culturales y simbólicas a partir de transformaciones identitarias a lo largo del tiempo.

En el censo de 2001 se identifican 2.549 hogares donde alguno de sus miembros se reconoce como descendiente o perteneciente a un pueblo indígena, dato que debe considerarse en base al abanico de posibilidades en la interpretación de la pregunta y del filtro subjetivo de los encuestados. Es necesario señalar dos aspectos importantes: en primer lugar, que ninguna de las opciones de pueblos indígenas (quizás pueda excluirse la general de diaguita-calchaquí) que proponía la encuesta, corresponde con la de las comunidades autorreconocidas actualmente en la provincia. Probablemente en la opción de "otros pueblos" se haya incorporado el pueblo tonocoté que aparecerá en la ECPI (Encuesta Complementaria de Pueblos Indígenas) en los años 2004-2005. En segundo lugar, el dato que 1.548 de estos hogares se encuentran en áreas urbanas tensiona el imaginario que generalmente ubica a estas poblaciones en áreas rurales.

21 La ECPI fue la segunda etapa de una estrategia metodológica integral que comenzó con el censo, tomando como referencia los hogares para luego constituirlos como marco del muestreo de la encuesta. En el caso de Santiago del Estero se localiza al pueblo diaguita/diaguita-calchaquí presente en diferentes zonas del país, y siendo parte de una región muestral que incluye a otras provincias como Córdoba, La Rioja, Santa Fe y 
Catamarca. Esto nos imposibilita contar con un número discriminado para la provincia. Por otra parte, los tonocoté se visibilizan por primera vez como pueblo reconocido en un relevamiento nacional con una población de 4.779, aunque no se dispone de información acerca de la unidad muestral, por lo que suponemos que pertenecen exclusivamente, o en su mayoría, al territorio provincial. Dentro de las categorías "otros" la encuesta contempla una variedad, como vilelas y abipones, que debido a la escasa cantidad de casos muestrales no se los expone, pero que pueden ser relevantes para la provincia. La inexactitud de los totales para Santiago del Estero y la ausencia de otros pueblos que luego iniciarán el autorreconocimiento evidencian lo incipiente del proceso de reetnización.

El censo del 2010 nos aproxima a un número más preciso y a una etapa más consolidada del autorreconocimiento donde se identifican otros pueblos, algunos de los cuales cambiaron de denominación y consiguieron personería jurídica, y otros que quizás son producto de respuestas a un reconocimiento más tangencial de la descendencia o de identificación con la lengua quichua como parte de la afirmación de su aboriginalidad. ${ }^{11}$

\begin{tabular}{|l|l|}
\hline Pueblo indígena u originario & Población indígena u originaria \\
\hline Total & 11.508 \\
\hline Tonocoté & 3.636 \\
\hline Diaguita-Calchaquí & 1.755 \\
\hline Lule & 1.196 \\
\hline Toba & 947 \\
\hline Quechua & 815 \\
\hline Atacama & 632 \\
\hline Guaraní & 480 \\
\hline Vilela & 359 \\
\hline Sanavirón & 350 \\
\hline Otros & 1.338 \\
\hline
\end{tabular}

Tabla $\mathrm{N}^{\circ} 1$. Población indígena $\mathrm{u}$ originaria por pueblo. Santiago del Estero, 2010

Fuente: Censo Nacional de Población, hogares y viviendas 2010. Pueblos originarios. Región Noroeste Argentino.

TABLA N 1

De esta manera, los últimos datos oficiales - totalmente desactualizados después de 11 años- nos muestran que 11.508 personas se autorreconocen como parte de un pueblo, es decir, un 1,3\% de la población de la provincia, siendo los de mayor peso demográfico los tonocoté, diaguita-calchaquí y lule. Actualmente los 6 pueblos que se reconocen con sus comunidades son: tonocoté, diaguita (cacano), lule-vilela, vilela, guaycurú y sanavirón, presentes en una extensa región que cubren los departamentos San Martín, Alberdi, Moreno, Guasayán, Loreto, Choya, Sarmiento, Capital, Copo, Loreto, Figueroa, Avellaneda y Juan Felipe Ibarra.

Este análisis histórico de los relevamientos indígenas nos permite trazar ciertos aspectos. En primer lugar, el descenso demográfico a partir del genocidio producto de las matanzas y de las explotaciones en el sistema de encomiendas que se reflejan en los 
números que van desde las tempranas crónicas y estimaciones hasta el último empadronamiento de 1807. En este punto aclaramos que, si bien no podemos realizar un seguimiento exhaustivo de la población debido a la calidad de las fuentes durante esos períodos, a lo que se suman los problemas para la precisión de la categoría hacia la etapa final de la Colonia, tampoco podemos desconocer el descenso poblacional señalado por las mismas autoridades coloniales en las fuentes tempranas. En segundo lugar, la maleabilidad de la categoría de indio o indígena y por lo tanto de los problemas para la identificación de esta población -sumado a procesos de blanqueamiento social hacia fines de la colonia- provocó que muchos indios sean categorizados como mestizos, iniciando así un largo proceso de invisibilización que se consolida en los censos nacionales del XIX al desmarcar a la población santiagueña como indígena. Finalmente, los últimos censos evidencian un proceso incipiente y continuo de autorreconocimiento como parte de un contexto de resarcimiento histórico y de reconocimiento de derechos que comenzó hacia mediados de los 90, a lo que habría que agregar los criterios de delimitación de la pertenencia étnica en el mismo instrumento censal que evidencian de alguna manera las propias representaciones estatales sobre lo indígena.

\section{La alteridad indígena en la formación de la identidad provincial}

Si bien el borramiento de la categoría indígena puede leerse como parte de un dispositivo discursivo enmarcado en relaciones de poder tendiente a crear subjetividades y con cierta función estratégica (Foucault, 1992), la producción discursiva intelectual y del campo político y cultural no pudo negarla y la terminó matizando para incorporarla como parte de una herencia de la identidad local. El proceso de desindianización, a partir de la desaparición de los pueblos de indios coloniales, fue consolidándose a lo largo del XIX cuando la alteridad pasó a estar exclusivamente en los bordes de la provincia y del otro lado de la frontera chaqueña. En este sentido, el último tercio de ese siglo se caracterizó por la incorporación de formas de producción capitalistas con la expansión de la modernidad en una sociedad caracterizada como tradicional (Tasso, 2007). La instalación de los ramales ferroviarios en una gran parte de llanura santiagueña posibilitó abrir las puertas y potenciar actividades como la industria azucarera, la alfalfa y los cereales, y, por supuesto, la extracción y venta de maderas del bosque nativo a partir de los obrajes en un contexto de expansión de la frontera chaqueña y de un creciente mercado de tierras. Es en este contexto de desarrollo capitalista provincial donde comienza a instalarse la preocupación por pensar la identidad en relación a la alteridad que representaban los indígenas del área chaqueña.

\section{Lo liminal del espacio y de las identidades indígenas}

Luego de haber sido un espacio fronterizo desde la Colonia, la zona del río Salado se fue progresivamente poblando hacia el este como consecuencia de distintos procesos económicos y ecológicos (condiciones del terreno para la ganadería, explotación forestal, etc.) durante el siglo XIX y principios del XX. Si bien la presencia indígena había constituido una problemática constante por los llamados "malones" en toda esa 
región, los distintos dispositivos militares y evangelizadores puestos en marcha por el Estado provincial y nacional provocaron de manera violenta el desplazamiento de estas poblaciones, lo que permitió a la provincia extender su territorio hacia al este. Los antecedentes militares y de contención sobre la población indígena pueden rastrearse casi durante todo ese siglo, pero se destacan las políticas hacia la segunda mitad con el gobierno de Manuel Taboada que evidenció una fuerte preocupación por la permeabilidad de las fronteras sobre el Salado y la consecuente inestabilidad de esa franja del territorio provincial. La designación de un jefe de fronteras y de emplazamiento de nuevos fortines como Doña Lorenza, Navicha, Esperanza y La Viuda, entre otros, responde a una política del Gobierno de la Confederación preocupado por restaurar un frente de fortines sobre el área para atender nuevamente a las fronteras del Chaco, descuidadas durante las guerras civiles (Schaller, 1986). ${ }^{12}$

La preocupación por resguardar la zona respondía, en principio, a la necesidad de repeler los ataques a las poblaciones criollas que sufrían el robo de ganado $\mathrm{y}$, paralelamente, asegurarse el tránsito para la comercialización con provincias del litoral y del noroeste. Uno de los proyectos más importantes fue la navegabilidad de este río impulsada por el capitán inglés Page, que tenía como uno de los principales obstáculos la presencia indígena. El agrimensor Amadeo Jacques en su excursión por el Bracho durante 1856 refleja esta preocupación con ciertos números. Pues, en poco más de un año, se contabilizaron seis invasiones con una suma de 66 muertos y 47 cautivos entre la población santiagueña "civilizada" (Jacques, 1857). De esta manera, la preocupación constante por la expansión territorial justificó una serie de campañas y expediciones a una escala mayor como la iniciada por Bosch en 1883, siendo gobernador del Territorio Nacional del Gran Chaco. Y un año más tarde, la de Victorica en su función de ministro de guerra de Roca. Sin dudas, esta fue la más importante, por la movilización de recursos y el apoyo del Congreso de la Nación, que buscaba la ocupación definitiva del Chaco. Cinco columnas militares partieron de distintos puntos de Córdoba, Resistencia y Formosa para encontrarse en el Bermejo, acompañadas de científicos e ingenieros que exploraban los terrenos para conocer las condiciones topográficas, ambientales y ecológicas y asegurarse así la explotación económica de estas tierras. Se trató de penetrar a un territorio todavía desconocido para el Estado nacional. El objetivo militar residía en doblegar y arrinconar a la población indígena hasta el Bermejo donde se estableció una línea de fortines. Esta campaña da inicio a la denominada conquista del "desierto verde" que tuvo su finalización hacia la segunda década del siglo XX con el genocidio indígena y su desterritorialización.

En paralelo a la campaña militar se promulgó la ley 1532 de organización de los territorios nacionales por la que se dividía al Chaco en dos gobernaciones: de Formosa y Chaco, y se fijaron nuevos límites que significaron para la provincia la extensión de la frontera hacia el este y por lo tanto de ampliar su territorio más allá del Salado. Sin embargo, los problemas de la frontera sur-este se agudizaban como consecuencia de la presencia y entraderas de abipones y montaraces en campos de familias criollas de Santiago del Estero y Santa Fe. El afincamiento de distintas tolderías en los límites interprovinciales y las formas de interacciones en zonas de frontera, que suponían estrategias combinadas de resistencia, negociación y parcial sometimiento, dejan en claro que estas sociedades indígenas lograron resistir a las distintas intervenciones militares y que refutaban cierto discurso acerca de la "liberación" completa del Chaco Austral. ${ }^{13}$ 
30 Al nuevo mapa de la geografía provincial hacia las últimas décadas del XIX se lo trata de comprender también desde una cartografía de las identidades. El espacio del profundo interior provincial y de la frontera implicaba toda una mirada en relación a cómo entender las costumbres de estas poblaciones desindianizadas, pero todavía sospechadas de un salvajismo que era necesario matizar discursivamente. Desde el discurso político intelectual se apostaba a una división entre civilizados santiagueños (o en proceso) y salvajes del Chaco Gualamba, tratando de simplificar y borrar toda una heterogeneidad que complejizaba ese dualismo. Esta diferenciación incluía a poblaciones rurales desindianizadas durante los primeros tiempos de ese siglo e incorporadas a las estancias como mano de obra, o sirviendo como jornaleros en los obrajes madereros, muchos de ellos asentados en los márgenes de los ríos y con una constante interacción con los indígenas chaqueños, pero también a poblaciones criollas que se instalaban al interior del Chaco en un intento de colonización de esas tierras, a los migrantes y "criollos" propietarios de industrias, quintas y estancias en la capital y otras localidades, y del otro lado, los indígenas chaqueños aún no civilizados que representaban la alteridad del santiagueño.

31 Las memorias descriptivas de Alejandro Gancedo (1885) y de Lorenzo Fazio (1889) hacia la década del 80 representan ese discurso que se preocupa por mostrar las potencialidades económicas de la provincia y de trazar un cuadro de la cultura e identidad local para exponerla hacia afuera. ${ }^{14}$ Sus empeños por construir una imagen de tierras prometedoras para el progreso y de atraer la migración como parte de un plan de colonización en diferentes zonas, pero principalmente del área chaqueña, refleja la constante preocupación por los avances indígenas en la frontera y los inconvenientes para el establecimiento de estancias en los fértiles campos del sur. Ambos reconocen que parte de la provincia se encuentra habitada por grupos indígenas a los que consideran ambiguamente como un peligro "menor" para esos tiempos, pero que le dedican algunos párrafos para advertir a las autoridades de los posibles frenos al plan de colonización.

32 Alejandro Gancedo no tiene empacho en emparentar a los indígenas chaqueños con los animales salvajes, clasificándolos como "mamíferos bimanos" (Gancedo 1885, p. 43) y situándolos en cercanías del fuerte Taboada sobre el Salado y donde este río se acerca al Dulce hasta llegar al límite con Santa Fe, y al igual que Fazio, señala que si bien se trata de pequeños grupos, una franja importante del oriente provincial se ve afectada por las formas de circulación y penetración de estas tribus a los campos y estancias criollas. En las arremetidas que realizan para contener sus avances en la "parte civilizada de la provincia" suelen ser reducidos y evangelizados en el catolicismo, reemplazando sus deidades, que generalmente son representadas por el "Inti" (sol en quichua), como señala Fazio (1889). Este dato es interesante para pensar -tomando con muchas precauciones la representación del autor- en cómo el uso del quichua por parte de las sociedades chaqueñas puede evidenciar los vínculos con las poblaciones mestizas santiagueñas, y en la posible mixtura de estos grupos llamados "montaraces".

En su Memoria Descriptiva, Gancedo establece la identidad del santiagueño a partir de diferentes grados de civilidad en un arco que va desde el ciudadano hasta el gaucho o paisano de zonas rurales. En un pasaje señala las costumbres del paisano del Salado (especialmente del departamento Copo, zona fronteriza) en cuanto a vestimenta y a prácticas vinculadas a fiestas de carnaval y navidad, en las que observa aún rastros de "salvajismo". La gradualidad de la civilidad parece observarla en correspondencia con 
las áreas de conquista y colonización temprana, donde percibe a poblaciones emprendedoras y con otros hábitos, diferenciándose de los espacios de frontera a los que llega a clasificar como "poco o nada civilizados" y donde el quichua funciona como lengua general al igual que en otras áreas con mayor "grado de civilidad" como Banda, Silípica, Loreto, Atamisqui y Salavina. En esa misma dirección, el trabajo asalariado a partir de establecimientos industriales reflejaba esa posibilidad de acceso a la ciudadanía y civilidad. La cultura del trabajo capitalista implicaba, para Lorenzo Fazio, una forma de desindianizarse cuando señala que los peones llegados en tren a los ingenios de la Capital ya habían dejado de ser "retoños errantes de tribus dispersas de quichuas" y que el dinero y el hábito del trabajo había cambiado drásticamente el estado de salvajismo: "Hé recordado á los peones de Contreras para demostrar la influencia civilizadora que ejerce el hábito del trabajo; cuando Contreras era un bosque, esos peones eran, ó podían compararse sin miedo de ofenderlos, á tantos indios mansos" (Fazio, 1889, p. 323).

Avanzados los primeros tiempos del siglo XX la formación de un discurso educativo se acopla en la preocupación por la definición de la identidad local. Maestros rurales como Medardo Moreno Saravia o Domingo Bravo se pronuncian a través de revistas, libros y periódicos respecto a las características de los pobladores de la campaña santiagueña. ${ }^{15}$ Las marcaciones culturales e identitarias, y solapadas con ellas las situaciones de abandono y precariedad de estos sectores, se legitiman en base a una hegemonía discursiva (Angenot, 2012) que comienza a instalarse a través de la escuela como uno de los dispositivos territoriales de estatalidad más significativos. Si bien desconocemos con precisión sus efectos simbólicos concretos sobre los propios imaginarios y las reelaboraciones identitarias de la población rural, tenemos indicios para sostener la circulación de un discurso legitimador de diferencias culturales y raciales, así como la necesidad de integrarlas en el marco de la identidad santiagueña (Bonetti, 2015).

Uno de los discursos más potentes y crudos lo encontramos en una cartilla que publica el maestro e inspector de escuelas Moreno Saravia hacia 1938 en su libro Escuela $y$ Patriotismo. ${ }^{16}$ Allí refiere cómo, supuestamente, la provincia y la región contaron con una baja presencia afromestiza y por lo tanto de una nula incidencia en la identidad local, con argumentos religiosos e históricos distorsionados al sostener que "Dios nos libró de los negros" (Moreno Saravia, 1938, p. 144). Esta repulsión a aceptar las influencias afro lo llevó a dedicarles palabras como "raza fea y grosera" y a postular, equivocadamente, que su peso demográfico fue insignificante debido a que los esclavos introducidos por el puerto de Buenos Aires eran trasladados al Alto Perú, y Santiago solo sirvió como un lugar de paso. Por otra parte, Saravia introduce una reflexión sobre lo que denomina "progreso y matriz de nuestra raza" señalando que la estirpe de la raza criolla fue progresivamente "impregnándose del espíritu europeo" y su base americana se observa en el mestizo. Es el mestizaje el lugar de definición de la identidad local, en este caso a través de una amalgama étnica que la conceptualiza como "lule-quichua-iberos".

Esta concepción del mestizo aparece con frecuencia en los discursos del periodo, incluso extendiéndose hasta la actualidad bajo otras categorías. Así, el maestro y lingüista Domingo Bravo (1988), en sus memorias sobre su desempeño como docente en la campaña santiagueña durante las décadas de los 30 y 40 , sostiene que el campesino es producto de una mezcla que denomina como la mixtura de la sangre indo-hispana, resaltando las características de ambas influencias; de lo indígena la resignación para el 
sufrimiento y del español el espíritu romántico; y de ambos el gaucho o criollo que lo identifica como el ascendiente intermedio de los niños escolares que observa en el medio rural.

En esta primera mitad del siglo XX se instala la preocupación entre académicos $\mathrm{y}$ científicos por el devenir de la identidad local y la necesidad de revisión de la historia como una forma de comprender el presente. Estos discursos pueden ser interpretados como parte de un relato de extinción indígena que se fue sedimentando desde el siglo XIX. Desde la arqueología fueron los hermanos Wagner los pioneros en la realización de excavaciones y de postular una teoría acerca del poblamiento temprano en la llanura santiagueña. Durante los primeros tiempos realizaron recolección de material arqueológico para luego ser enviados a distintos museos del país y de Europa, hasta que en 1927 logran que el gobierno provincial, con un sostenido apoyo de la asociación de escritores e intelectuales locales "La Brasa", financie sus excavaciones, lo que dará como resultado su principal obra de 1934 denominada La civilización Chaco-santiagueña y sus correlaciones con el viejo y el nuevo mundo. Si bien este trabajo tuvo una importante recepción en la provincia -en un contexto atravesado por la búsqueda y la definición del lugar de la nación en una tensión entre centro y periferia- desde la comunidad arqueológica nacional se deslegitimaba y criticaba severamente a las interpretaciones de los Wagner. La teoría se basaba en atribuir la existencia de una gran civilización en el territorio provincial con una remota antigüedad y que se había extinguido mucho antes de la conquista española. Aquellos "indios salvajes y bárbaros" que los colonizadores describían en sus crónicas no tenía relación alguna con aquella gran civilización y cuyos restos emergían en las excavaciones o a través de las erosiones naturales.

Más allá de la endeble cientificidad de los postulados de los hermanos franceses, esta interpretación alimentaba la particularidad local que posicionaba a la provincia en un estatus histórico distintivo permeado por un pasado de grandeza y que por lo tanto la diferenciaba en el campo de las identidades provinciales. ${ }^{17}$ Esta perspectiva evidencia un distanciamiento, una ruptura respecto a las poblaciones rurales contemporáneas; pues no veían en el campesino santiagueño ningún tipo de descendencia indígena en general y mucho menos en relación a la civilización imaginada. Los restos indígenas como evidencia de su exterminio no permitían levantar la mirada hacia el presente sin caer en la concepción del mestizaje y la aculturación, en el mejor de los casos.

Dentro del campo de las ciencias del folklore -y en vínculo con los Wagner- se sitúa la mirada de dos intelectuales significativos de La Brasa como Bernardo Canal Feijóo y Orestes Di Lullo, que daban continuidad a las preocupaciones instaladas por Ricardo Rojas en los primeros años del siglo (Farberman, 2010). Canal Feijóo se preocuparía por aspectos del denominado folklore y cultura santiagueña considerando al indígena como herencia vernácula en la configuración de la cultura provincial, a la que denomina como "fenómeno santiagueño". Percibía lo indio en la expresión popular que se centraba en la religiosidad, creencias, en el acervo de tradiciones, en la producción artesanal, y particularmente en el quichua. En su Ensayo sobre la expresión popular artística en Santiago de 1937 observa la cultura indígena en términos de "sobrevivencia" de continuidades residuales ya mestizadas; y la persistencia y continuidad de lo que llamó "medida espiritual del aborigen", reflejada también en la lengua quichua donde parece observar una mayor continuidad con las poblaciones rurales, al observar la coincidencia de los mayores focos quichuistas con las zonas de mayor tradición y 
arqueología indígena. Lo que debemos considerar, más allá de esta perspectiva, es que se trataba de un pasado objetivado a través de la cultura en el presente, ya mezclado y alterado, y de un sujeto ausente; pues, como señala en su interpretación de la fiesta mestiza de San Esteban y en relación a la práctica de "corrida de indios", se trata de una categoría simbólica en el plano etnográfico e histórico, donde se evidencian "indios simbólicos" sin existencia real en el presente.

Orestes Di Lullo, por su parte, está influenciado por una fuerte perspectiva hispanista en su lectura sobre la historia santiagueña. Fundador y primer director del Instituto de Lingüística, Folklore y Arqueología, perteneciente en ese momento a la Universidad Nacional de Tucumán (1953-1973), se dedicó a la revisión de la historia local para explicar el presente. Desde el folklore, la historia y la sociología realizó un exhaustivo trabajo de campo en zonas rurales de la provincia denunciado el estancamiento y la explotación del bosque nativo. Su propia posición hispanista se cristaliza en varias de sus obras donde les otorga un peso significativo a instituciones coloniales como la estancia jesuítica, en tanto espacio contenedor de las diferencias. Al igual que Canal Feijóo, interpreta al santiagueño y su cultura como producto de una mezcla de herencias, cada cual con peso propio. En un pasaje de su obra sostiene que "en la formación del carácter del santiagueño necesariamente han debido influir las distintas razas que se mezclaron para producir el típico racial actual" (Di Lullo, 1983, p. 43). En tal sentido, del español heredó un tipo de ocio sustentado en un "querer ser más que hacer", en cambio del indio, a quien adjudica una vida salvaje, le otorga un carácter infantil y de alguna manera lo sentencia a que "solo sirve para la guerra, la caza y la pesca (...)" (p. 44). Sin embargo, señala algunas características especiales para el indígena de esta región, caracterizado por su dulzura y docilidad. Al describir al tipo actual de santiagueño se refiere al mestizo, a una hibridación física, psíquica y cultural, considerándolo aún no definido por las sucesivas mezclas que quebraron la "pureza" de las etnias.

41 Como vemos, el discurso sobre la identidad provincial se fue sedimentando progresivamente desde el siglo XIX. Si bien las preocupaciones y los intereses varían en relación al lugar de enunciación de estos intelectuales, maestros rurales y científicos, las coincidencias residen en identificar al mestizo como el "prototipo" del santiagueño, señalando la herencia indo-hispana y excluyendo, en parte, al componente afromestizo y al inmigrante europeo del siglo XIX. El santiagueño se convierte así en la síntesis de las identidades coloniales y en un sujeto generalmente subalternizado en el espacio social. En estos discursos observamos el borramiento de la presencia indígena (aunque muchas veces ambigua como lo vimos en algunos de estos intelectuales) en la jurisdicción santiagueña, en todo caso situándola en aquellos grupos chaqueños que todavía tenían una fuerte presencia en el área fronteriza. Una provincia "libre de indios" hacia el inicio del siglo XX evidencia una fuerte autonegación de las poblaciones rurales a identificarse bajo esa condición en paralelo a un discurso de la extinción.

\section{La etnicidad indígena del campesinado santiagueño}

La primera pregunta que nos surge es cómo pensar las identidades en un contexto actual de expansión capitalista y transnacionalización de la cultura (Canclini, 1985), y en tal sentido es importante advertir cómo operan ciertas nociones incrustadas en los sentidos comunes al considerarla como un "punto fijo del pensamiento y del ser" (Hall, 
2010 [1992]), algo que nos brinda estabilidad en una coyuntura de transformaciones; una suerte de garantía de continuidad independiente de los cambios históricos. Este lenguaje para entender la identidad se relaciona con cierta búsqueda de "autenticidad interior" a partir de las propias experiencias de los sujetos. En esta dirección Stuart Hall (2010 [1992]) nos ayuda a pensar ciertos descentramientos teóricos del sentido fijista de la identidad de los cuales nos interesa puntualizar dos para nuestro caso. En primer lugar, el propio Marx nos señala que, si bien podemos producir la historia, no siempre lo hacemos en las condiciones deseadas, por lo que existen cuestiones de la identidad que el sujeto no puede construir; ya que siempre estamos construidos en parte por los discursos que nos anteceden y que constituyen condicionamientos estructurales que operan sobre la autonomía de los sujetos que enuncian y proclaman una determinada identidad. Por otra parte, el esquema saussureano de que todo discurso se sitúa dentro de las relaciones de la lengua y en tal sentido arrastramos significados y sentidos del pasado inscriptos en ella; lo que implica una disputa y desplazamiento de ciertos significados instalados como los que genera la misma palabra "indio". Es necesario considerar, siguiendo al mismo Hall, que la identidad no puede ser considerada como un núcleo interno del sujeto y que no se desarrolla por fuera de las representaciones construidas en el mismo discurso; es decir que la identidad no existe por fuera de su producción discursiva.

En los tiempos contemporáneos las etnicidades emergentes o llamadas como nuevas etnicidades se constituyen como el puente entre la identidad y la diferencia. En ese sentido Hall (2010 [1989]) la entiende como la posicionalidad de los sujetos para el pronunciamiento identitario, principalmente a partir de las formas de vinculación con el pasado como parte necesaria de la construcción de la propia etnicidad; por lo que los actuales procesos de reetnización implican una narrativa histórica que pueda "recuperar" un pasado no vivenciado, (auto) negado, donde las herencias y tradiciones culturales se constituyen, de cierta manera, en un diacrítico de esa identidad. Aquí el pasado se convierte en un recurso necesario y potente. En esta nueva etnicidad la relación con el pasado es compleja, al que es necesario interpelarlo, salir de la lógica esencialista y aprender a contar las propias historias para reconstruirlo (Hall, 2010 [1989]). Los pueblos originarios como etnicidad emergente necesitan esa articulación con un pasado que se presenta contado y objetivado por la sociedad dominante.

En el caso de Santiago del Estero esta búsqueda de etnicidad se realizó en base a memorias indias del campesinado; representaciones ambiguas y contradictorias del pasado indígena respecto a las propias identidades en las que se lo presenta como una otredad y mismidad al mismo tiempo. Son recurrentes los discursos, tanto de poblaciones autorreconocidas como de aquellos sectores campesinos, que interpretan el pasado indígena, materializado en la huella arqueológica o en las historias familiares/comunales, como un "otro" al referirse a "los indios de antes", o bien cuando se posicionan desde un lugar de la descendencia y de la continuidad histórica para referenciarlos como "nuestros ancestros". Esta ambigüedad atraviesa a los sectores rurales indígenas y campesinos, donde la diferencia reside en las formas actuales de etnización y en lo que ello conllevó en términos de reconstruir una comunidad étnica a partir de estructuras de gobierno y de rituales andinos como la Pachamama como parte de esa recuperación. Por lo demás, el campesinado comparte una historia común, la lengua quichua ${ }^{18} \mathrm{y}$ las mismas memorias indígenas. En un capítulo del programa "Pueblos originarios" de Canal Encuentro, pobladores de la 
comunidad vilela de Rincón del Saladillo evidencian y reconocen esas ambigüedades propias de los efectos de un relato histórico hegemónico de la extinción indígena. En un pasaje, uno de sus integrantes reflexiona en torno a la producción de estos discursos a propósito de la escuela:

Te querían hacer sentir que vos no eras indio, que eras (...) ya eras cruza o eras descendiente de (...) Podés haber sido descendiente de español, yo no puedo decir que no. Pero nosotros mucho más que creer en la sangre española, nosotros creemos que somos descendencia india. Hasta nos han hecho creer que eso no era verdad. ${ }^{19}$

El campesinado no etnizado mantiene una relación parecida con el pasado indígena donde la figura del mezclao (mestizo) se vuelve importante. Es así que el mestizaje funciona como un dispositivo discursivo en muchas zonas rurales de la provincia para definirse identitariamente cuando se interpela sobre el pasado indígena, y que se silencia cuando las categorías de campesino/a, productor/a o simplemente poblador/a asegura una membresía que no se cuestiona (Bonetti, 2016). ${ }^{20}$ De esta manera, y en cierto sentido, tanto campesino como indígena se vuelven categorías prácticamente intercambiables. La primera representa un sujeto producto de la síntesis y desigualdad colonial, desmarcado étnicamente, y reconvertido como sujeto político en la defensa de las tierras que comenzó a gestarse en las décadas de los 70 y 80 y que se cristalizó con el surgimiento del MOCASE; mientras que la segunda representa una retorno a la etnicidad prehispánica y colonial resignificada en los tiempos actuales como una posibilidad más para posicionarse desde el lugar de la identidad y donde el Estado tiene un peso importante. En un trabajo reciente, Concha Merlo (2021) establece cierta diferenciación en la producción identitaria de aboriginalidad de un caso particular de la zona chaqueña de la provincia que, aunque consideramos que debe entenderse de una forma más matizada y no tan esquemática de las identidades "puertas hacia afuera" y "puertas hacia adentro", nos permite continuar profundizando en nuestra concepción acerca de la construcción de memorias y articulaciones locales campesinas sobre y con lo indígena y las influencias estatales que se solapan en la producción de la etnicidad. ${ }^{21}$

En su análisis sobre las identidades de comunidades indígenas y de procesos de etnogénesis en América Latina, Christian Gros (1999) refiere a la construcción de una "nueva frontera étnica" en el continente y al papel de distintos actores en la conformación de la misma: organizaciones indígenas, ONG, intelectuales y académicos, y hasta ciertas multinacionales y entidades financieras. Allí señala el rol activo del Estado en la producción de la etnicidad que nos parece crucial para entender los procesos locales. Más allá de la capacidad de agencia de las comunidades, el proceso de autorreconocimiento como pueblo indígena emerge en un contexto neoliberal que, paradójicamente, reconoce derechos culturales y territoriales como en la reforma constitucional de 1994. Es decir, estas políticas estatales condicionaron las emergencias indígenas en el marco de un espacio político favorable para la legitimación de estas "nuevas identidades", donde comenzaba a imponerse un derecho positivo y un valor a las diferencias culturales. El Estado se vuelve indispensable en términos de la participación activa en la construcción del sujeto étnico, que, como señala Gros (1999), le permite constituir un interlocutor válido para la intervención de sus políticas y conseguir legitimidad en su implementación; es de este modo que también el Estado se posiciona desde un discurso políticamente correcto como garante de la diversidad cultural, aunque con deudas históricas que no logran subsanar las desigualdades presentes. 

histórica de un sector rural importante que trata de reconstruir el pasado, que, como todo ejercicio de memoria, está filtrado por las subjetividades y demandas del presente, lo que implica necesariamente una resignificación del ser indígena a partir de la búsqueda y reafirmación de la etnicidad y de la necesaria legitimación estatal. Es en este marco que debemos entender ritualidades y ceremonias, así como denominaciones de autoridades y estructuras políticas, desconocidas en el medio rural hasta hace unos 20 años atrás. En este sentido, como observa Lorena Rodríguez (2004) en su análisis acerca de la discontinuidad del pasado de la comunidad de ingamanas en Catamarca, los agujeros de la memoria son rellenados a partir de elementos que no necesariamente son parte constitutiva de ese pasado y de ese contexto, pero que son igualmente útiles. ${ }^{22}$ Es de este modo que el pasado desconocido, fragmentado, silenciado o borrado por las políticas del olvido debe reinventarse, y los huecos de la memoria comienzan a llenarse a partir de fragmentos y elementos que otorgan etnicidad. Los propios pueblos reconocen, como en el caso de los tonocoté, "haber perdido su identidad" como consecuencia de la conquista y de otros hechos que provocaron genocidios y etnocidios; aunque asumen la aboriginalidad a partir de una mixtura de tradiciones de la cultura campesina, la lengua quichua y elementos andinos como la denominación de la autoridad Kamáchej (proveniente del dialecto cuzqueño-boliviano) o la forma de celebración de la Pachamama (Alderetes, 2007).

ender que toda identidad es política porque supone posicionalidad del sujeto en el espacio social, se vuelve imprescindible para comprender determinados usos políticos que podemos hacer de ella; bien como lo destacaba Alejandro Isla (2003) al referirse a los usos políticos de la memoria y la identidad para el caso de Amaicha del Valle. En nuestro caso, la reetnización sirvió para otorgar mayor politicidad a los reclamos históricos por la tenencia de la tierra y los territorios acudiendo al reconocimiento de la preexistencia y a la figura de la propiedad comunitaria aún discutida por sus potenciales efectos jurídicos para las propias comunidades, pero sobre todo aún por los propios jueces que desconocen la legislación vigente, e incluso la existencia de 6 pueblos con más de 70 comunidades. Son varios los fallos judiciales que ordenaron remates de grandes extensiones de tierras donde viven las propias comunidades como en El Rancho, en el departamento Figueroa, o desalojos que luego son frenados por instancias superiores como en el caso de la comunidad Potrillo Pozón del mismo departamento que ponen continuamente en riesgo la posesión de esas tierras. Solo citamos dos ejemplos de los muchos que suceden en una gran extensión de la geografía provincial.

La identidad indígena también se nuclea en el movimiento campesino. El MOCASE Vía Campesina contiene a pueblos y comunidades que lograron reetnizarse y que, de a poco, van ganando un espacio significativo donde lo indígena se convierte en una identidad que no reemplaza a la de campesino, sino que la complementa, le otorga un estatus y profundidad histórica que generalmente no se reconoce en la primera. Asimismo, es necesario advertir que gran parte del campesinado no se ha reetnizado, lo que no implica que aparezcan subterráneamente identificaciones indígenas cuando se interpela sobre el pasado de la comunidad, constituyéndose en una de las múltiples formas en las que se autodefinen. 


\section{Reflexiones finales}

50 Nuestra comprensión sobre el proceso de etnogénesis en la provincia se centró en dos argumentaciones principales. Por un lado, el peso del Estado y de un contexto políticojurídico determinante en el inicio de la reetnización de una parte del campesinado santiagueño. Por otro, un proceso de invisibilización discursiva que comienza a instalarse hacia el siglo XIX y que se expande durante el XX teniendo como protagonistas a ciertos agentes estatales como maestros rurales, políticos e intelectuales, que contribuyeron a la formación de subjetividades colectivas, aunque sin éxito, para socavar memorias indígenas del campesinado que se sedimentaron desde la Colonia y sobre la cual se constituyen las nuevas etnicidades.

51 Partir de una historicidad de las identidades étnicas para el abordaje del fenómeno actual nos permitió plantear diversos aspectos en la producción de identidades y diferencias que nos parece importante enunciar de la siguiente manera:

52 - La ilegibilidad de lo indígena en las estadísticas y relevamientos poblaciones. Como observamos, durante el siglo XIX desaparece como categoría en el plano oficial y es subsumida en otras bajo connotaciones raciales o de clase como parte de un proceso de desindianización de aquellos viejos indios coloniales; y cuya reemergencia con los censos nacionales del 2001, la encuesta complementaria de pueblos indígenas de 2004-2005 y del censo del 2010, evidencia el gradual proceso de autorreconocimiento. De esta manera las categorías de indio/indígena/pueblo originario se vuelven elásticas en los distintos contextos de producción y con ciertas ambigüedades en su definición.

53 -Hacia fines del XIX la política discursiva en la construcción de una identidad provincial evidencia una diversidad interna que se arrastra desde la Colonia y que motiva la reflexión del campo intelectual en el intento de explicar los orígenes y el presente de aquella población rural desindianizada y que debía integrarse a la comunidad local imaginada (Anderson, 2006). Estos discursos profundizaron la idea de la extinción, y si bien tuvieron su efecto simbólico en términos de asegurarse cierta reelaboración identitaria, convivieron con categorías sociales de definición de lo indígena que aún persisten, tal como se expresan en las memorias de sectores campesinos.

54 - La participación del Estado nacional y provincial, pero principalmente del primero, en la constitución de la etnicidad le posibilitó ordenar y gestionar la diversidad, pero principalmente legitimar sus propias políticas haciendo visible una otredad constituida. Algunos pueblos construyeron su etnicidad recurriendo a discursos y prácticas ancestrales -incluso de otros contextos- reproduciendo la imagen que el propio occidente había elaborado sobre lo indígena y la que el Estado muchas veces necesita para legitimar las diferencias culturales e intervenir políticamente.

55 - La identidad indígena en términos étnicos implica una novedad para el campesinado santiagueño que convive con algunas tensiones propias de un extenso proceso histórico de negación y de representaciones sobre el pasado indígena que se presenta en un marco de ambigüedad en tanto forma de identificación. Esta nueva membresía posibilitó una serie de derechos culturales y territoriales que potencian los reclamos hacia los desalojos y las invasiones de empresarios que constantemente hostigan a los sectores rurales. El sentido político de las identidades se vuelve indispensable en condiciones de desigualdad, aunque también produce diferencias con el campesinado 
no etnizado con el cual comparte gran parte de la historia, las memorias y la lengua, pero que queda en desventaja en tanto ausencia de una legislación que los contemple como un sujeto diverso y de derecho. En todo caso, resta esperar la aplicación de los derechos del campesino que fuera aprobado por la ONU en el 2018.

-La etnogénesis representa un resurgimiento en base a experiencias y memorias donde se trata de reconstruir un pasado para articularlo con las circunstancias del presente y evidenciar que las identidades no son fijas, ni estáticas, ni esenciales (por más que en ocasiones puedan reproducir esta idea), sino que se cocinan en el horno de la historia como producto de relaciones de poder en distintos contextos de la historia local y nacional. La etnicidad emergente representa esa búsqueda del pasado y donde los pueblos, como dice Hall (2010 [1989]), son los que deben "aprender" a contar su propia historia en un presente complicado y atravesado por conflictos territoriales, avances del agronegocio y de ausencia de políticas públicas, como en educación intercultural bilingüe y en otros ámbitos que garanticen con mayor profundidad los derechos de los pueblos indígenas/campesinos.

\section{Fuentes:}

Archivo General de Indias

Archivo General de la Nación

Archivo histórico de Santiago del Estero

Archivo del Obispado de Santiago del Estero

Dirección General de Patrimonio Cultural. Santiago del Estero. Periódico La Reforma. 1900.

Página web INDEC

Página web de Canal Encuentro

Página web https://archive.org/ 1885. Expedición llevada a cabo bajo el comando inmediato del Exmo. Sr. Ministro de Guerra y Marina General Dr. Don Benjamín Victorica

\section{BIBLIOGRAPHY}

Alderetes, J. (2007). La construcción de una identidad indígena: implicancias lingüísticas. Trabajo presentado en Primer lanzamiento de la Red Nacional de Investigadores sobre Discriminación, INADI, Ciudad Autónoma de Buenos Aires. Recuperado de http://www.adilq.com.ar/ponencia31.htm.

Anderson, B. (2006). Comunidades imaginadas. Reflexiones sobre el origen y la difusión del nacionalismo. México: Fondo de Cultura Económica.

Andreani, H. (2014). Quichuas, picardías y zorros. Conflictos y tácticas en una comunidad bilingüe. Santiago del Estero: EDUNSE. 
Angenot, M. (2012). El discurso social. Los límites históricos de lo pensable y lo decible. Buenos Aires: Siglo XXI editores.

Beckett, J. (1988). Introduction. En J. Beckett (Ed.), Past and present. The construction of Aboriginality, (pp. 1-10). Canberra: Aboriginal. Studies Press.

Boccara, G. (2001). Mundos nuevos en las fronteras del nuevo mundo. Relectura de los procesos coloniales de etnogénesis, etnificación y mestizaje en tiempos de globalización. E-review UMR 8565 Nuevo Mundo, Mundos Nuevos: CNRS-CERMA.

Bonetti, C. (2015). Indios, mestizos y Santiagueños: discursos identitarios acerca de la población rural de Santiago del Estero en la segunda mitad del siglo XIX y principios del XX. Trabajo y Sociedad, 25, 281-293.

Bonetti, C. (2016). Memorias y alteridades indias. Discursos y marcas indígenas en zonas rurales de Santiago del Estero. Tucumán: Humanitas.

Bonfil Batalla, G. (1972). El concepto de indio en América: una categoría de la situación colonial. Anales de Antropología, 9, 105-24.

Bravo, D. (1988). Cuaderno de impresiones. Recuerdos de la escuela. Santiago del Estero: Herca talleres gráficos.

Briones, C. (1996). Culturas, identidades y fronteras: una mirada desde las producciones del cuarto mundo. Revista de Ciencias Sociales, 5, 121-133.

Canal Feijóo, B. (2012 [1937]). Ensayo sobre la expresión popular artística en Santiago. Santiago del Estero: Subsecretaría de Cultura de la provincia de Santiago del Estero.

Concha Merlo, P. (2021). Discursos de aboriginalidad entre los Lule-vilela del MOCASE. Tensiones entre la demanda estatal de etnicidad y apertura indigenista de las identidades criollas. Corpus. Archivos virtuales de la alteridad americana, 11(1), 1-29.

Di Lullo, O. (1983). La razón del folklore. Santiago del Estero: Publicación realizada por el Gobierno de la Provincia.

Escolar, D. (2007). Los dones étnicos de la nación. Identidades huarpe y modos de producción de soberanía en Argentina. Buenos Aires: Prometeo libros.

Farberman, J. (1998). El peso de la continuidad. Tierra, trabajo familiar y migraciones en Santiago del Estero. Un estado de la cuestión. Población y Sociedad, 5, 165-186.

Farberman, J. (2008). Santiago del Estero y sus pueblos de indios. De las Ordenanzas de Alfaro (1612) a las guerras de independencia. Andes, 19, 225-250.

Farberman, J. (2010). Magia, brujería y cultura popular. De la colonia al siglo XX. Buenos Aires: Sudamericana.

Farberman, J. y Taboada, C. (2012). Las sociedades indígenas del territorio santiagueño: apuntes iniciales desde la arqueología y la historia. Período prehispánico tardío y colonial temprano. Runa, XXXIII(2), 113-132.

Farberman, J. (2019). De "naciones" a "indios" y de "indios" a "paisanos". Sujetos y prácticas indígenas en Santiago del Estero, siglos XVI a XIX. En D. Escolar y L. Rodríguez (Comps.), Más allá de la extinción. Identidades indígenas en la Argentina criolla siglos XVIII-XX, (pp. 40-85). Buenos Aires: Paradigma Indicial.

Fazio, L. (1889). Memoria descriptiva de la provincia de Santiago del Estero. Buenos Aires: Compañía Sudamericana de Billetes de Banco. 
Foucault, M. (1992). Microfísica del poder. Madrid: Las Ediciones de La Piqueta.

Gancedo, A. (1885). Memoria descriptiva de Santiago del Estero. Buenos Aires: De Stiller \& Laass.

García Canclini, N. (1985). Cultura y sociedad. Una Introducción. Secretaría de Educación Pública de México. Recuperado de https://perio.unlp.edu.ar/catedras/antropologia/wp-content/ uploads/sites/117/2020/05/2.P-Garcia-Canclini-Cultura-y-sociedad-una-introduccion-1-15.pdf

Gordillo, G. y Hirsch, S. (2010). La presencia ausente: Invisibilizaciones, políticas estatales y emergencias indígenas en Argentina. En G. Gordillo y S. Hirsch (Comp.), Movilizaciones indígenas e identidades en disputa en la Argentina, (pp. 15-38). Buenos Aires: La Crujía Ediciones.

Gros, C. (1999). Ser diferente por (para) ser moderno, o las paradojas de la identidad: Algunas reflexiones sobre la construcción de una nueva frontera étnica en América Latina. Análisis político, $36,3-20$.

Grosso, J. (2008). Indios muertos, negros invisibles. Hegemonía, identidad y añoranza. Córdoba: Encuentro Grupo Editor.

Hall, S. (2010 [1989]). Etnicidad: identidad y diferencia. En E. Restrepo, C. Walsh y V. Vich (Eds.), Sin garantías. Trayectorias y problemáticas en estudios culturales, (pp. 339-348). Colombia: Envión Editores Publicada como Ethnicity: identity and difference. Radical America, 23, 4 9-20, 1989. Traducido por Eduardo Restrepo.

Hall, S. (2010 [1992]). La cuestión de la identidad cultural. En E. Restrepo, C. Walsh y V. Vich (Eds.), Sin garantías. Trayectorias y problemáticas en estudios culturales, (pp. 363-404). Colombia: Envión Editores. The Question of Cultural Identity. En S. Hall, D. Held, T. McGrew (Eds.), Modernity and its Futures. Cambridge: Polity. [Publicado en la presente compilación como La cuestión de la identidad cultural].

Isla, A. (2003). Los usos políticos de la memoria y la identidad. Estudios atacameños, 26, 35-44.

Jacques, A. (1857). Excursión al río Salado y el Chaco. Confederación argentina. París: De Pillet Fils Ainé.

Martínez, A., Taboada, C. y Auat, A. (2011). Los hermanos Wagner, entre ciencia, mito y poesía. Arqueología, campo arqueológico nacional y construcción de identidad en Santiago del Estero, 1920-1940. Bernal: Editorial de Universidad Nacional de Quilmes.

Moreno Saravia, M. (1938). Escuela y Patriotismo. Santiago del Estero: Tipografía Zampieri.

Pucci, R. (1998). El tamaño de la población aborigen del Tucumán en la época de la conquista: Balance de un problema y propuesta de nueva estimación. Población y Sociedad, 5, 239-270.

Rodríguez, L. (2004). Reflexiones acerca de la memoria y los usos del pasado a partir del análisis de un caso en el noroeste argentino. Departamento Santa María (Provincia de Catamarca). Cuadernos de Antropología Social, 20, 151-168.

Rodríguez, L. (2019). Alteridades indígenas en Tucumán en el paso de la colonia a la república. Un acercamiento a la configuración de la matriz provincial de identidad. En P. López Caballero y Ch. Giudicelli (Eds.), Regímenes de alteridad. Estados-nación y alteridades indígenas en América Latina, 1810-1950, (pp. 157-191). Villa María: Editorial Universitaria Villa María.

Schaller, E. (1986). La colonización del territorio nacional del Chaco en el período 1896-1921. Cuadernos de Geohistoria, 12, 1-156.

Scott, J. (1998). Seeing Like a State. How Certain Schemes to Improve the Human Condition Have Failed. London: Yale University Press.

Sturtevant, W. (1971). Creek into Seminole: North American Indians. En E. Leacock y N. Lurie (Eds.), Historical Perspective, (pp. 92-128). Nueva York: Random House. 
Tasso, A. (2007). Ferrocarril, quebracho y alfalfa. Un ciclo de agricultura capitalista en Santiago del Estero, 1870-1940. Córdoba: Alción Editorial.

Togo, J., Garay, L. y Bonetti, C. (2009). Linajes y poder en los pueblos de indios del siglo XVIII en Santiago del Estero. Indoamérica, 3, 53-74.

Wagner E. R. y D. L. (1934). La Civilización Chaco-Santiagueña y sus Correlaciones con las del Viejo y Nuevo Mundo. Buenos Aires: Compañia Impresora Argentina.

\section{NOTES}

1. Nos parece interesante la idea de cómo la aboriginalidad representa un tipo específico de etnicidad, como forma histórica de alteridad donde la nación tuvo que construirse en relación a un otro nativo.

2. En lo etnohistórico véanse los trabajos de Farberman (1998, 2008); Togo, Garay y Bonetti (2009); Farberman y Taboada (2012), entre otros. Desde una perspectiva etnográfica e histórica Grosso (2008), Bonetti (2016). Con respecto al término "memorias indias" nos referimos a las formas de representación del pasado indígena por parte de poblaciones campesinas en las que se manifiesta una ambigüedad y tensión en torno a esa identificación. Para profundizar ver el trabajo sobre memorias y alteridades de Bonetti (2016).

Recientemente, un trabajo de Concha Merlo (2021) aborda, desde una perspectiva multiescalar, la movilización de ciertos significados emergentes en los lule-vilela del MOCASE Vía Campesina (VC) sobre lo indígena en el marco de ciertas producciones discursivas de la identidad.

3. Esta apreciación se basa en observaciones propias sobre ciertas situaciones y de cierto discurso que circula por ámbitos académicos y en algunas ocasiones en las propias zonas rurales. La marca de la "extinción indígena" continúa siendo de peso en Santiago, al no comprenderse en muchos casos el proceso de autorreconocimiento y las nuevas etnicidades.

4. Optamos por referirnos a la facción "Vía Campesina" del MOCASE, dado que si bien hubo un reciente proceso de unificación con el MOCASE "Histórico", nuevamente se provocaron rupturas y ambos sectores se referencian como MOCASE. Al mismo tiempo es importante mencionar que el Vía Campesina fue el que avanzó en procesos de identificación indígena del campesinado y mayores articulaciones con otros actores, proceso que la otra facción está comenzando a implementar.

5. Son conocidas las descripciones de Martin Dobrizzhofer y Florian Paucke acerca de los abipones y mocovíes del área chaqueña.

6. Cartas de gobernadores (1607) ref. PARES-- AGI,CHARCAS,26,R.8,N.41; ims. 9 y 10.

7. Audiencia de Charcas, CACh, 632. Documento conocido como "Censo de 1608"; transcripción basada en una fotocopia del documento original conservado en el Archivo Nacional de Bolivia, Sucre. Recuperado de https://asi-dixeron.org/sdecenso1608.php?fun=trx

8. Un padrón de 1614 da cuenta de la convivencia entre los nativos del pueblo y otras dos parcialidades de Quiloamira y de los Vacagas. Confirmación de Encomienda de Azingasta. 1623. Archivo General de Indias. Charcas, 101, N. 31. Recuperado de PARES. http://pares.mcu.es/ ParesBusquedas/servlets/Control_servlet?accion=3\&txt_id_desc_ud=341371\&fromagenda=N 9. Padrón de 1807. Legajo ํㅡ 33 -Archivo General de la Nación.

10. Libro de casamientos de Indios, Negros y Mulatos del Curato de San Miguel de Soconcho 1783-1814. Archivo del Obispado de Santiago del Estero.

11. Un dato que nos permite esa interpretación es que más del $85 \%$ de la población autoidentificada como "quechua" reside en áreas urbanas.

12. En 1856 se nombra como jefe de fronteras a Antonino Taboada, hermano del gobernador. 
13. En una carta de noviembre de 1884 Victorica relata su llegada a Cangayé sobre el Bermejo: "Hasta aquí queda el camino hecho, bien marcado y seguro, y puede garantirse que todo el chaco Austral queda libre. Si vagan aun pequeños grupos de indígenas en los bosques, familias, no tribus, no tardarán en someterse, porque han perdido los medios de subsistir de la caza, quemando los campos y de la pezca por la ocupación del rio" (Campaña del Chaco, 1885, p. 168).

14. La obra de Gancedo obedece a un decreto dictado por el Gobierno Nacional a través del Departamento de Agricultura con el fin de exhibirse en la Exposición Continental las muestras de los productos naturales y elaborados en todo el país, por lo que promueve la publicación de descripciones de las provincias. "Además siendo también conveniente para estimular toda clase de estudios e investigaciones que tengan por objeto el fomento de la inmigración y el progreso de las industrias". En tanto la Memoria de Fazio constituye una continuación de la de Gancedo.

15. En 1900 el periódico provincial la Reforma publica una nota donde publicita y celebra la aparición de la revista $\mathrm{La}$ voz del desierto cuyo director es Moreno Saravia. Allí refiere a la necesidad de "colonizar los Copos". Una de las revistas más importes fue Picada publicada entre 1939 y1949.

16. Medardo Moreno Saravia fue director de distintas escuelas rurales de la zona del Salado y se preocupó por ciertos debates educativos y políticos. Fue director del Consejo de Educación y parte de su formación académica la realizó en Europa. Este maestro rural, trascendió su profesión para convertirse en un intelectual que tuvo participación en algunas revistas educativas y se ocupó de aéreas de gestión. En tal sentido, y teniendo en cuenta su formación e inserción, es que entendemos la capacidad performativa de su discurso.

17. Para profundizar la discusión en torno a la tarea científica de los Wagner, su relación con la construcción de la identidad de lo indígena y un análisis de la formación del campo intelectual en la provincia, véase el trabajo de Martínez, Auat y Taboada (2011).

18. Para profundizar sobre el quichua y la producción de ciertas identidades ver Alderetes (2007) y Andreani (2014).

19. Canal Encuentro (2009). Pueblos originarios Tercera temporada. Vilela: Pueblo en tránsito. Recuperado de http://encuentro.gob.ar/programas/serie/8008/97

20. En un trabajo de campo que realicé en la zona del río Dulce, departamento Silípica, se evidencia que el mestizaje también forma parte del discurso identitario del campesinado cuando se interpela la relación con el pasado indígena. En algunas ocasiones la categoría de "mezclao" se hacía visible para referirse tangencialmente a la ascendencia indígena.

21. Concha Merlo analiza el caso de los lule-vilelas del Mocase VC. En sus conclusiones sostiene una diferenciación de un posicionamiento identitario con la presencia estatal y otro en función de una aboriginalidad de "entre casa".

22. La autora toma a Bastide que -en sus estudios sobre las religiones africanas en Brasil (1970) - se pregunta sobre las discontinuidades de la memoria y cómo es resuelta por los sujetos; y cuya respuesta la obtiene a través del concepto de bricolage de Lévi-Strauss.

\section{ABSTRACTS}

This article addresses the current processes of ethnogenesis in the province of Santiago del Estero from a perspective focused on the historicity of ethnic identities. Faced with certain denialist positions of indigenous identities, considering them without historical continuity, or those situated in the pure subjectivity of the actors, the work problematizes the forms of 
visibility and invisibility of the indigenous during the 19th and early 20th centuries to understand identities as emerging from power relations and the conditions of possibility for their legitimacy in the present. In this sense, it problematizes the construction of current ethnicity based on the role of the state and the parallel activation of Indian memories of the local peasantry. Methodologically, we worked with various documentary sources and based on previous ethnographic work carried out with sectors of the peasantry.

Este artículo aborda los actuales procesos de etnogénesis en la provincia de Santiago del Estero desde una perspectiva centrada en la historicidad de las identidades étnicas. Frente a ciertas posturas negacionistas de las identidades indígenas, por considerarlas sin continuidad histórica, o de aquellas situadas en la pura subjetividad de los actores, el trabajo problematiza las formas de visibilización e invisibilización de lo indígena durante el siglo XIX y principios del XX para entender las identidades como emergentes de relaciones de poder y de las condiciones de posibilidad para su legitimación en el presente. En tal sentido, problematiza la construcción de la etnicidad actual a partir del rol del Estado y de la activación paralela de memorias indias del campesinado local. Metodológicamente se trabajó con diversas fuentes documentales y en base a trabajos etnográficos previos realizados con sectores del campesinado.

INDEX

Keywords: Ethnogenesis, historicity, invisibility, Santiago del Estero

Palabras claves: Etnogénesis, historicidad, invisibilización, Santiago del Estero

\section{AUTHOR}

\section{CARLOS BONETTI}

Instituto de Lingüística, Folklore y Arqueología. Universidad Nacional de Santiago del Estero. Argentina

Correo electrónico: carlybonetti@gmail.com 